\title{
REQUISITOS Y REQUERIMIENTOS DE LAS COLABORACIONES PARA LA REVISTA PALOBRA
}

\section{DOCENTES, INVESTIGADORES Y PROFESIONALES}

Los interesados en participar como articulistas de la revista deberán cumplir con los siguientes criterios y requerimientos básicos en los textos que presentan a consideración del Comité Editorial, los cuales se ajustan a la clasificación y los patrones establecidos por COLCIENCIAS para esta clase de documentos.

\section{TIPOS DE ARTÍCULOS}

Las colaboraciones presentadas al Comité Editorial de Palobra tendrán un formato que se ajuste a la tipología establecida por Publindex-Colciencias, 2006.

- Artículo de Investigación Científica, documento que presenta resultados originales de proyectos de investigación terminados. Su estructura generalmente contempla cuatro (4) apartes: introducción, metodología, resultados y conclusiones.

- Artículo de Reflexión, Documento que presenta resultados de investigación terminada por el autor desde una perspectiva analítica, interpretativa ó crítica, sobre un tema específico, recurriendo a fuentes originales.

Estos dos tipos de artículos tendrán una extensión máxima total de 12 páginas; los siguientes, tendrán una extensión máxima total de 10 páginas:

- Artículo de Revisión: Documento resultado de una investigación terminada por el autor donde se analizan, sistematizan e integran los resultados de investigaciones publicadas o no publicadas, sobre un campo temático, con el fin de dar cuenta de avances y tendencias de desarrollo. Se caracteriza por fundamentarse en una revisión bibliográfica rigurosa.

- Artículo de Revisión de Tema: Cuando se expone el resultado de una revisión crítica de la bibliografía sobre un tema que no esté soportada por una investigación científica por parte del autor.

- Documento de reflexión no derivado inmediatamente de investigación ("Ensayo").

- Documentos de Trabajo: Son textos que adelantan avances teóricos, 
metodológicos y empíricos sobre casos específicos provenientes de investigaciones en marcha que se someten a escrutinio público.

- Testimonios: Transcripciones de documentos históricos (públicos y privados) no publicados y/o materiales etnográficos (biográficos, relatos, etc.) que se publican (con la debida autorización de las fuentes) para su divulgación.

- Crónicas: Documentos que recoge impresiones e interpretaciones del autor sobre circunstancias contextuales presentes.

- Notas: Notas breves y reseñas informativas (máximo dos páginas) sobre eventos de interés científico-académico provenientes de las actividades ordinarias de docencia, investigación y extensión generados por y/o en los que participe la Facultad de Ciencias Sociales y Educación y la Universidad de Cartagena por intermedio de sus estudiantes, cuerpo docente y administrativo.

\section{REGLAMENTO DE PUBLICACIONES}

- Deben ir precedidos de dos (2) resúmenes (en inglés y español), que no debe superar las 200 palabras, incluyendo 5 palabras claves, en ambos idiomas. Contarán con una introducción, subcapítulos y conclusiones o recomendaciones y notas bibliográficas.

- Las notas y referencias deben incluirse al pie de cada página (no al final del artículo). La bibliografía no deberá exceder los 15 títulos.

- Los artículos deben estar escritos a espacio y medio, en fuente Times New Roman, de 12 puntos. Deberán ser entregados en formato Word (2000 en adelante), en medio magnético y una copia impresa con la autorización del autor para su publicación.

- Las fotografías, que se propongan para ser incluidas en cualquier tipo de artículo o texto de Palobra deberán estar reveladas en blanco y negro, sino son digitales. Las fotos deberán tener referenciado el autor y el asunto. Lo mismo se aplica para los gráficos, diagramas o cualquier material ilustrativo.

- Las palabras en idioma extranjero deben ir en cursiva.

- Las citas deben ir entre comillas. En caso de superar los 8 renglones, se harán en párrafo centrado.

- Todas las referencias bibliográficas citadas en los textos deben aparecer al final del artículo. La bibliografía deberá hacerse siguiendo las siguientes recomendaciones:

o Libro: Apellidos del autor (Mayúsculas), nombre del autor en minúsculas. año de edición entre paréntesis. Título del libro en cursiva. nombre de la 
editorial. lugar de edición, página/s (Pág. o Págs.)

o Artículo de revista: Apellidos del autor (Mayúsculas), nombre del autor en minúsculas. año de edición entre paréntesis. Título del artículo en cursiva, Preposición "En": Nombre de la revista en cursiva. nombre de la editorial, lugar de edición, volumen (Vol.), número de la revista (No.), mes/es entre paréntesis, páginas que comprende el artículo dentro de la revista o página citada (pág. o págs.)

o Prensa: Apellidos del autor (Mayúsculas), nombre. Título del artículo en cursiva. Preposición "En": Nombre del periódico en cursiva, lugar de edición, fecha, página/s (pág. o págs.)

o Documentos de archivos: Denominación del archivo (la primera vez completa y después en iniciales), sección, legajo, expediente, fecha.

o Publicaciones en Internet: Apellidos del autor (Mayúsculas), nombre del autor en minúsculas. fecha de la publicación entre paréntesis, Título del artículo en cursiva. dirección de la página web, la inscripción: "Fecha de consulta" y el dato respectivo.

- Una vez citada determinada obra, del modo descrito, puede emplearse en ulteriores citas la forma abreviada que incluye sólo apellido del autor, año de publicación y página donde aparece la cita. Ej.: (Ortiz, 1998: 20)

- Los textos incluidos en la bibliografía se deben presentar alfabéticamente por el primer apellido de los autores y en orden cronológico ascendente para cada autor.

- Si es artículo de una ponencia, se indicará en las notas al final de la primera página del texto.

- Los agradecimientos, en donde los autores reconocen el apoyo al desarrollo del estudio o investigación, son voluntarios. Se debe colocar al final del texto principal en las notas.

Todo artículo debe incluir los datos biográficos en hoja aparte: Nombre y apellidos, país, fecha de nacimiento, documento de identidad, afiliación institucional (Dependencia y Subdependencia), nivel de escolaridad, publicaciones de los últimos 5 años.

Los autores deben manifestar por escrito su consentimiento para publicar el artículo en la revista, esta nota de aceptación debe estar firmada y autenticada por cada uno de ellos.

Los evaluadores tendrán en cuenta los siguientes criterios: 
- Novedad del tema

- Relevancia social del tema

- Estructura lógica y coherencia

- Coherencia entre los campos temáticos y articulo

- Argumentación, orden y lógica de exposición

- Redacción y claridad escritural

El concepto que los evaluadores pueden emitir puede ser:

- Aprobado sin correcciones

- Aprobado con recomendaciones

- No aprobado

La revista se reserva el derecho a publicar el artículo de acuerdo a la evaluación que realice el par evaluador. El comité editorial de la revista se reserva el derecho de hacer correcciones menores de estilo.

En caso de ser aprobados con recomendaciones, se le enviará una carta al autor (es), anexando dichos conceptos. Los autores deben hacer las correcciones y devolver el artículo (corregido) en un plazo máximo de 15 días.

Los autores recibirán dos (2) ejemplares del número en el que participaron

\section{CAMPOS TEMÁTICOS}

Los textos enviados al Comité Editorial deberán vincularse a asuntos localizables dentro de los campos temáticos siguientes:

- CONVIVENCIA Y DESARROLLO HUMANO. PROCESOS DE INCLUSIÓN Y EXCLUSIÓN SOCIO - POLITICA

- procesos y aCtores en la construcción de lo público y LO PRIVADO. IMAGINARIOS, REPRESENTACIONES Y DISCURSOS.

- historia DE LA EDUCACIÓN LATINOAMERICANA, COLOMBIANA y REGIONAL.

- INVESTIGACION EN EDUCACION. PEDAGOGIA.

- trabajo social, contexto y desarRollo

- SOCIEDAD Y TERRITORIO. ESTUDIOS LOCALES, RURALES Y URBANOS.

- MEdios de COMUNiCACIÓN, GLOBALIZACIÓN Y DEMOCRACIA.

- DESPLAZAMIENTO Y REHABILITACION. 
Palobra tiene una distribución local, regional y nacional, por intermedio de venta y canje con universidades, bibliotecas e instituciones y organizaciones de carácter académico, científico e investigativo y puntos de venta en eventos académicos y científicos. Además cuenta con una versión virtual colgada en la página WEB de la Universidad de Cartagena ww.unicartagena.edu.co/revistas. htm

\section{ESTUDIANTES}

Los siguientes son los requisitos y requerimientos básicos a cumplir por los textos de los estudiantes de la Facultad de Ciencias Sociales y Educación interesados en participar como articulistas de la revista PALOBRA.

\section{TIPOS DE ARTÍCUILOS}

Las colaboraciones presentadas al Comité Editorial de Palobra tendrán un formato que se ajuste a la siguiente tipología:

- Artículo de Revisión de Tema: Cuando se expone el resultado de una revisión crítica de la bibliografía sobre un tema que no esté soportado por una investigación científica por parte del(os) autor(es) del artículo.

- Documentos Académicos, que presentan los resultados de un proceso de intervención social que forma parte integral del proceso formativo del estudiante y en el que ha participado activamente. Este tipo de artículos deberá conllevar un aporte creativo y original a la reflexión en el campo científico y profesional del estudiante.

En todos los casos, el artículo propuesto a Palobra deberá contar con el aval académico del o los docentes que orientaron dicho trabajo.

Estos tipos de artículos tendrán una extensión máxima total de 6 páginas. Los artículos serán recibidos por el Comité Editorial si no exceden este tope.

También podrán aportarse a la Revista para su evaluación:

- Reseñas bibliográficas, de libros básicos en la formación y reflexión social que signifiquen un aporte significativo a la comprensión de la realidad social contemporánea internacional, nacional, regional y o local pertinente a las problemáticas abordadas por el estudiante en su proceso de formación. 
Deberán haber sido publicados en los últimos 3 años con relación al momento de la elaboración de la reseña. Esta tendrá un máximo de una (1) página.

Se solicita a los Estudiantes en general que aporten a la Revista en cada número:

- Notas: Notas breves y reseñas informativas (máximo una (1) página) sobre eventos de interés científico-académico provenientes de las actividades ordinarias de docencia, investigación y extensión generados por y/o en los que participe la Facultad de Ciencias Sociales y Educación y la Universidad de Cartagena por intermedio de sus estudiantes, cuerpo docente $y$ administrativo.

\section{PROCEDIMIENTO PARA RECEPCION DE ARTICULOS POR EL COMITÉ EDITORIAL}

Todos los artículos presentados a consideración del Comité Editorial de Palobra deberán ajustarse a los siguientes procedimientos:

Los artículos derivados de procesos de intervención y prácticas profesionales, en marcha o culminados, dirigidos por docentes de la Facultad como gestores principales, deberán contar con el aval académico del respectivo.

Se sugiere a los articulistas de las otras modalidades que gestionen dicho aval con sus respectivos docentes.

Una vez recibidos estos textos por parte del Comité Editorial, serán sometidos a la evaluación regular del comité editorial de la Revista.

Los dos artículos que el Comité Editorial conceptúe que cumplen en mayor grado con los criterios editoriales, metodológicos y de contenido serán publicados por la Revista en el próximo número. La Revista se reserva el derecho a publicar el o los artículos de acuerdo a la evaluación que el comité realice.

Los artículos deben ser enviados por los autores con una nota de aceptación de su publicación en la revista, firmada por cada uno de ellos.

Los derechos de autor en todos los casos serán de los articulistas así como la responsabilidad pública por sus contenidos. 


\section{REGLAMENTO EDITORIAL PARA PUBBLICACION DE COLABORACIONES}

- Deben ir precedidos de dos (2) resúmenes (en inglés y español), que no debe superar los 10 renglones, incluyendo 5 palabras claves, en ambos idiomas. Contarán con una introducción, subcapítulos y conclusiones o recomendaciones y notas bibliográficas.

- Las notas y referencia deben incluirse al pie de cada página (no al final del artículo). La bibliografía no deberá exceder los 15 títulos.

- Los artículos deben estar escritos a espacio y medio, en fuente Times New Roman, de 12 puntos. Deberán ser entregados en Word (2000 en adelante, en medio magnético) y dos (2) copias impresas con la autorización del autor para su publicación.

- Las fotografías, que no son digitales, propuestas para ser incluidas en cualquier tipo de artículo o texto de Palobra deberán estar reveladas en blanco y negro. Las fotos deberán tener referenciado el auto, el asunto y fecha. Lo mismo se aplica para los gráficos, diagramas o cualquier material ilustrativo.

- Las palabras en idioma extranjero deben ir en cursiva.

- Las citas deben ir entre comillas. En caso de superar los 8 renglones, se harán en párrafo centrado.

- Todas las referencias bibliográficas citadas en los textos deben aparecer al final del artículo. La bibliografía deberá hacerse siguiendo las siguientes recomendaciones:

o Libro: Apellidos del autor (Mayúsculas), nombre del autor en minúsculas, año de edición entre paréntesis, Título del libro en cursiva, nombre de la editorial, lugar de edición, página/s (pág. o págs.)

o Artículo de revista: Apellidos del autor (Mayúsculas), nombre del autor en minúsculas, año de edición entre paréntesis, Título del artículo en cursiva, Preposición "En": Nombre de la revista en cursiva, nombre de la editorial, lugar de edición, volumen (Vol.), número de la revista (No.), mes/es entre paréntesis, páginas que comprende el artículo dentro de la revista o página citada (pág. o págs.)

o Prensa: Apellidos del autor (Mayúsculas), nombre, Título del artículo en cursiva, Preposición "En": Nombre del periódico en cursiva, lugar de edición, fecha, página/s (pág. o págs.)

o Documentos de archivos: Denominación del archivo (la primera vez completa y después en iniciales), sección, legajo, expediente, fecha.

o Publicaciones en Internet: Apellidos del autor (Mayúsculas), nombre del autor en minúsculas, fecha de la publicación entre paréntesis, Título del 
artículo en cursiva, dirección de la página web, la inscripción: "Fecha de consulta" y el dato respectivo.

- Una vez citada determinada obra, del modo descrito, puede emplearse en ulteriores citas la forma abreviada que incluye sólo apellido del autor, año de publicación y página donde aparece la cita. Ej.: (Ortiz, 1998: 20)

- Los textos incluidos en la bibliografía se deben presentar alfabéticamente por el primer apellido de los autores y en orden cronológico ascendente para cada autor. No es necesario repetir en la bibliografía los textos mencionados en las citas.

- Si es artículo de una ponencia, se indicará en las notas de pie al inicio del texto.

- Agradecimientos, en donde los autores reconocen el apoyo al desarrollo del estudio o investigación, son voluntarios. Se debe colocar al final del texto principal en las notas.

Todo artículo debe incluir los datos biográficos del autor (es) en hoja aparte: Nombre y apellidos, país, fecha de nacimiento, documento de identidad, afiliación institucional (programa académico, facultad, universidad), nivel de escolaridad, publicaciones de los últimos 3 años. Adscripción a grupo de investigación al que pertenece y categorización según Colciencias.

En caso de ser aprobados con recomendaciones, se le enviará una carta al autor (es), anexando dichos conceptos. Los autores deben hacer las correcciones y devolver el artículo (corregido) en un plazo máximo de 15 días.

Los autores deben manifestar por escrito su consentimiento para publicar el artículo en la revista, esta nota de aceptación debe estar firmada y autenticada por cada uno de ellos.

Los autores recibirán dos (2) ejemplares del número en el que participaron.

\section{CAMPOS TEMÁTICOS}

Los textos enviados al Comité Editorial deberán vincularse a asuntos localizables dentro de los campos temáticos siguientes:

- CONVIVENCIA Y DESARROLLO HUMANO. PROCESOS DE INCLUSIÓN Y EXCLUSIÓN SOCIO - POLITICA

Palobrano. 10 Agosto/2009 
- pRocesos y ACTORES EN LA CONSTRUCCiÓN DE LO PÚBLiCO Y LO PRIVADO. IMAGINARIOS, REPRESENTACIONES Y DISCURSOS.

- historia DE LA EDUCACIÓN LATINOAMERICANA, COLOMBIANA y REGIONAL.

- INVESTIGACION EN EDUCACION. PEDAGOGIA.

- tRABAJO SOCIAL, CONTEXTO y DESARROLLO

- SOCIEDAD Y TERRITORIO. ESTUDIOS LOCALES, RURALES Y URBANOS.

- MEDIOS DE COMUNICACIÓN, GLOBALIZACIÓN Y DEMOCRACIA.

- DESPLAZAMIENTO Y REHABILITACION.

Palobra tiene una distribución local, regional y nacional, por intermedio de venta y canje con universidades, bibliotecas e instituciones y organizaciones de carácter académico, científico e investigativo y puntos de venta en eventos académicos y científicos. Además cuenta con una versión virtual que cuelga en la página WEB de la Universidad de Cartagena ww.unicartagena.edu.co/ revistas.htm

Los artículos, colaboraciones, documentos y correspondencia pueden ser dirigidos a:

Comité Editorial

Revista Palobra

Facultad de Ciencias Sociales y Educación

Universidad de Cartagena

Centro Carrera $6^{\mathrm{a}} \mathrm{N}^{\mathrm{o}} 36-100$.

Telefax 6655706

e-mail: departamentodeinvestigacionfcsye@yahoo.es

revistapalobra@unicartagena.edu.co

Comité Editorial

\section{Palobra}


La impresión de la revista se realizó en papel Kimberly Blanco Nórdico de 200 gramos para portada, y páginas interiores en Propal-libro 115 gramos. Para la composición general de textos, títulos y subtítulos se empleó la tipografía Carmina. Se aplicaron los programas Word 2003 para la edición de textos, Corel X3 para elaboración digital del logo, Photoshop CS2 para el retoque y edición de imágenes exploradas, el escaner BenQ para la captura de imágenes exploradas e Indesign CS2 para composición de páginas. Con un tiraje de 1.000 ejemplares en su Décimo número, la revista Palobra de la Facultad de Ciencias Sociales y Educación de la Universidad de Cartagena se terminó de imprimir en Agosto del año 2009 en Cartagena de Indias, Colombia. 
